\title{
33. Karyotype and Banding Analyses on Haploid Males of the Honey Bee (Apis mellifera)
}

\author{
By Hidehiro Hoshiba \\ Daito Bunka University, Daiichi High School, Itabashi, Tokyo \\ (Communicated by Sajiro Makino, M. J. A., May 12, 1984)
}

Cytological studies on Apis mellifera have been published by several investigators (Meves, 1907; Nachtssheim, 1913; Sanderson and Hall, 1958; Kerr, 1972). They observed 16 chromosomes in the male and 32 in the female.

Karyotype analyses in this genus were reported in haploid males of A. mellifera (Hoshiba and Kusanagi, 1978), in diploid males of this species (Hoshiba, 1979), and in both diploid and haploid males of A. cerana japonica (Hoshiba et al., 1981).

Details are presented in this paper on further karyological studies by means of the G- and C-banding techniques on A. mellifera male.

Materials and methods. Testes from young larvae (3 to 4 instar larvae) of $A$. mellifera $\mathrm{L}$. (golden Italian race) were dissected out when they were in spermatogonial division (somatic division). They were pretreated by hypotonic-colchicine $(0.4 \% \mathrm{KCl}, 0.01 \%$ colchicin) solution for 30 min and fixed in acetic acid-methanol (1:3). Preparations were made by the usual air-dry method, and stained by Giemsa. They were decoloured in acetic methanol and then, BSG and tripsin techniques of Sumner et al. (1972) and Seabright (1971) were applied for C- and G-banding.

Nomenclature of the chromosomes followed the system described by Levan et al. (1964).

Results and discussion. The chromosome number of the haploid set was 16 and they consist of 4 metacentrics (nos. 1-4), 12 submetaor subtelocentrics. This results were not identical with the previous study by Hoshiba and Kusanagi (1978). This may be due to the material, i.e., they used the meiotic (reproductive) cells of the testes, whereas this study used somatic cells (spermatogonia). The cells in the somatic division made it possible to observe more punctual chromosome morphology. This spermatogonial division was prolonged until 4 instar, and the final number of gonium cells per cyst were 32 by 5 multiple diviations. The karyogram, G- and C-banding patterns were illustrated in Figs. 1 and 2, respectively.

G-banding patterns so far as no. 1 to no. 6 and no. 14 to no. 16 


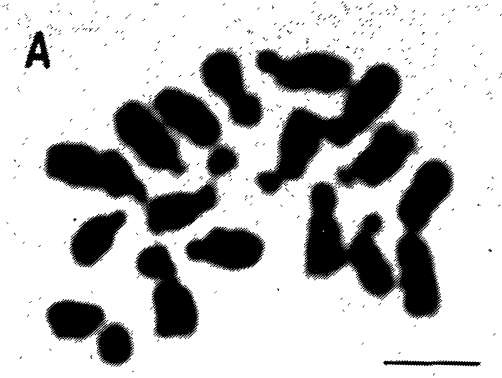

B

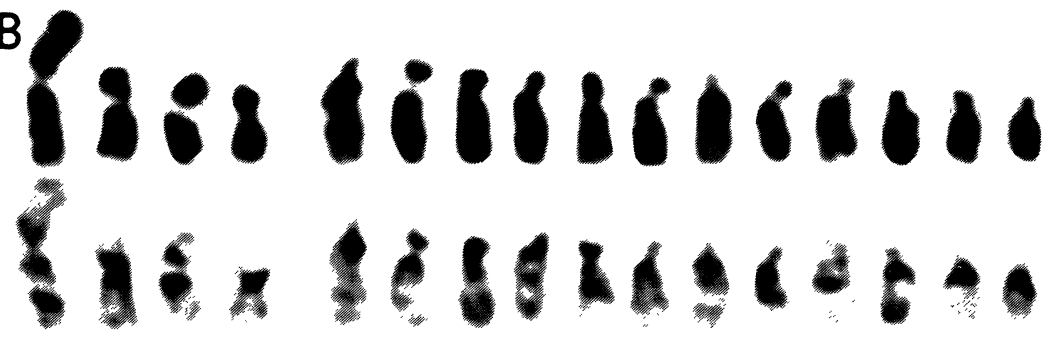

Fig. 1. Mitotic metaphase chromosomes of Apis mellifera (A) and its Gbanding karyotype pattern. (B) Bar indicates $2.5 \mu \mathrm{m}$.
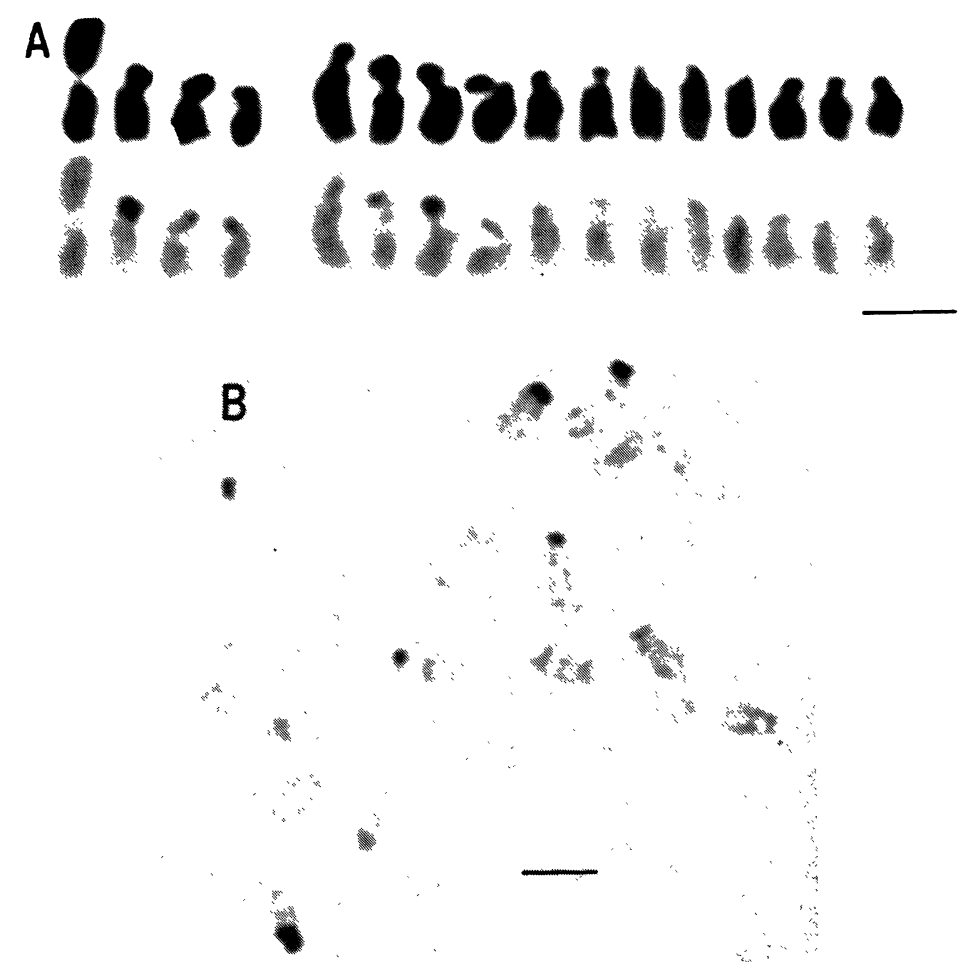

Fig. 2. C-banding pattern of haploid male of Apis mellifera (A, mitotic division; B, Meiosis I). Bars indicate $2.5 \mu \mathrm{m}$. 
were concerned, they were stably distinguished.

Nos. 2, 3, 4, 6, 7 and one from no. 8 to no. 16 had C-bands. These were more distinct in the meiotic division (Fig. 2B). Chromosomes no. 2 and no. 6 were stained much stronger, but they seemed not to indicate any sign of sex chromosomes.

Summary. Chromosomes of spermatogonial cells from young larvae of Apis mellifera were analyzed by means of G- and C-banding techniques. They consist of 4 meta-centrics and 12 submeta- or subtelo-centrics. G-banding patterns so far as no. 1 to no. 6 and no. 14 to no. 16 were concerned, they were stably distinguished.

Nos. 2, 3, 4, 6, 7 and one from no. 8 to no. 16 showed C-bands. Even with these banding techniques, no sex chromosomes were found in this study.

Acknowledgements. The author wishes to express his sincere appreciation to Emeritus Professor, Dr. Sajiro Makino, M. J. A., for his helpful suggestions for the improvement of this manuscript. He is also greatly indebted to following professors; Drs. Ichiji Okada, Seiroku Sakai, Hisashi Yamamoto and the late Dr. Akio Kusanagi.

\section{References}

Fahrenhorst, H. (1977) : Apidologie, 8, 89-100.

Hoshiba, H. (1979) : XXVII Int. Beekeep. Congr., 73-74.

Hoshiba, H., and A. Kusanagi (1978) : J. apic. Res., 17, 105-109.

Hoshiba, H., I. Okada, and A. Kusanagi (1981) : ibid., 20, 143-147.

Kerr, W. E. (1972) : J. Kans. ent. Soc., 45, 111-112.

Levan, A., K. Fredga, and A. A. Sandberg (1964) : Hereditas, 52, 201-220.

Meves, F. (1907) : Arch. mikr. Anat., 70, 414.

Nachtscheim, H. (1913) : Arch. Zellforsch., 11, 169.

Sanderson, A. R., and D. W. Hall (1948): Nature, 162, 34-35.

Seabright, M. (1971) : Lancet, ii, 971-972.

Sumner, A. T., H. J. Evans, and R. A. Buckland (1971) : Nature, 232, 31-32. 